\title{
УЧЁТ И СИСТЕМАТИЗАЦИЯ ВЕЩЕСТВЕННЫХ ДОКАЗАТЕЛЬСТВ В МВД РОССИИ С ПРИМЕНЕНИЕМ ИНФОРМАЦИОННЫХ ТЕХНОЛОГИЙ
}

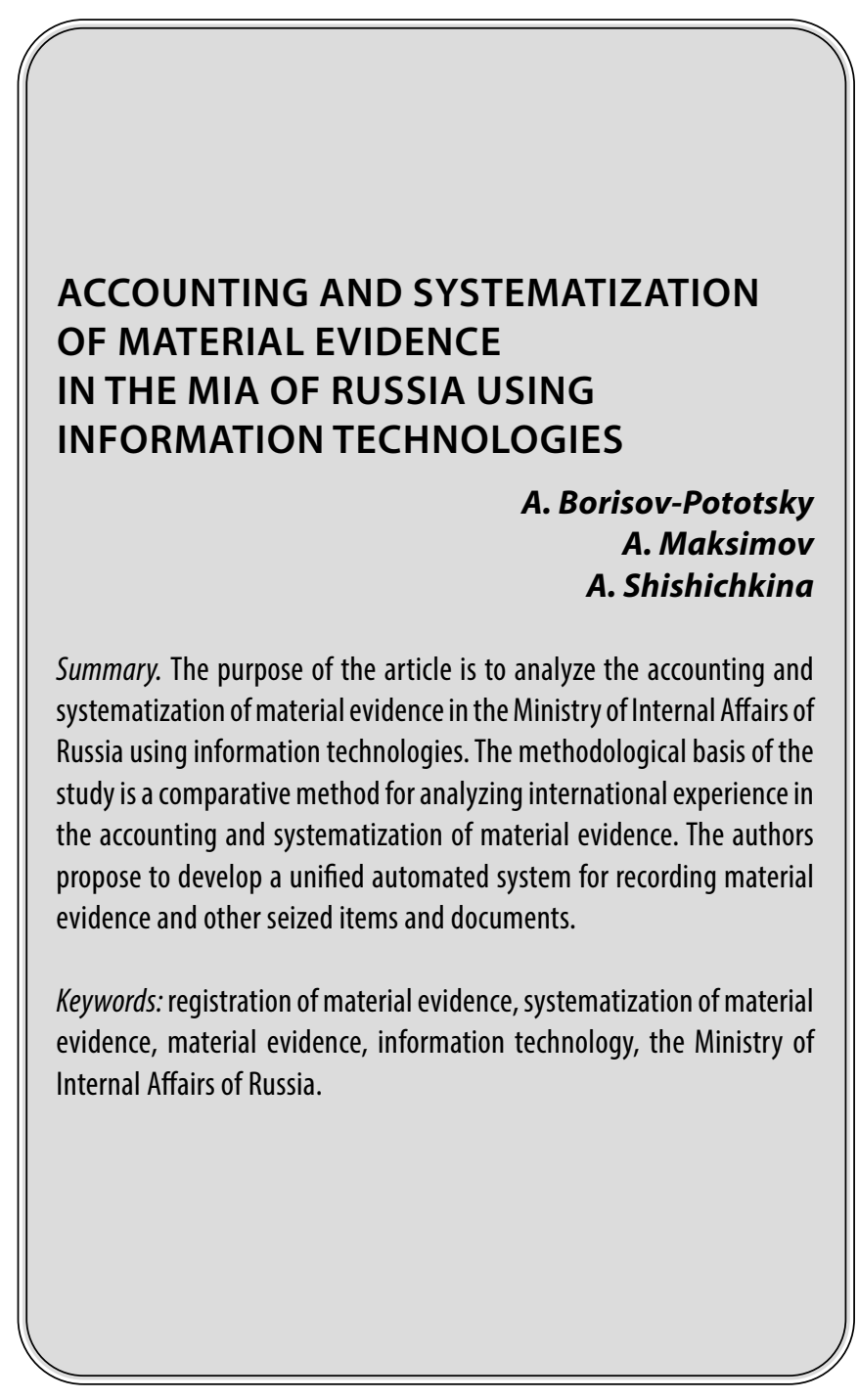

$\Phi$ ормирование вещественных доказательств и их использование в уголовном производстве невозможно без осуществления вспомогательной, обеспечивающей деятельности, ориентированной на сохранение самого материального носителя и его доказательных признаков. Кроме того, хранение вещественных доказательств является не только гарантией реализации задач уголовного судопроизводства, закрепленных в Уголовном кодексе РФ, но и необходимым условием соблюдения имущественных прав лиц, вещи которых были изъяты как вещественные доказательства в уголовном производстве. Проблема хранения
Борисов-Потоцкий Андрей Сергеевич

ФКУ «Научно-производственное объединение «Специальная техника и связь» Министерства внутренних дел Российской Федерации, Москва borisov_pototskiy_@spbu.su

Максимов Андрей Сергеевич ФКУ «Научно-производственное объединение «Специальная техника и связь» Министерства внутренних дел Российской Федерачии, Москва

Шишичкина Алена Вячеславовна

ГУ по вопросам миграции Министерства внутренних дел Российской Федерации, Москва

Аннотация. Целью статьи является анализ учета и систематизации вещественных доказательств в МВД России с использованием информационных технологий. Методологической базой исследования выступает сравнительный метод для анализ международного опыта в учете и систематизации вещественных доказательств. Авторами предлагается разработать единую автоматизированную систему учета вещественных доказательств и иных изъятых предметов и документов.

Ключевые слова: учет вещественных доказательств, систематизация вещественных доказательств, вещественные доказательства, информационные технологии, МВД России.

вещественных доказательств была предметом исследования некоторых отечественных и зарубежных ученых: Д.Т. Арабули, Е.Е. Головкина, С.А. Ковальчука, А.А. Рясова, Ю.В. Худяковой, С.С. Черновой, А.С.Шалякиной и других [1-7]. В тоже время системное исследование хранения вещественных доказательств с использованием информационных технологий не проводилось.

Развитие технологий сбора, анализа и хранения данных, обмена ими, управления социальными и производственными процессами осуществляется на основе внедрения современных информационных техно- 
логий. Быстрый рост объёма хранимых данных и, что еще более существенно, необходимость быстрой их обработки, способствует развитию коммуникационных технологий [6]. Цели, задачи и меры по реализации внутренней и внешней политики Российской Федерации в сфере применения информационных и коммуникационных технологий отражены в Указе Президента Российской Федерации от 9 мая 2017 г. № 203 «О Стратегии развития информационного общества в Российской Федерации на 2017-2030 годы» [1]. Объектом исследования данной работы является оценка возможности и определения оптимальных путей решений учета вещественных доказательств и иных изъятых предметов и документов, а также добровольно сданных и найденных предметов, вещей и документов предусматривающего, в том числе, идентификацию изъятого имущества в МВД России с применением информационных и телекоммуникационных технологий. Предметом исследования является организация учета вещественных доказательств в МВД России [2].

Преступность в сфере цифровых технологий вышла на новый уровень, и появились новые ее виды в киберпространстве. А правосудие на уровень отставало, так как в уголовном и гражданском праве не была разработана система электронных доказательств. Если они подписаны надлежащим образом, то принимаются судом наравне с бумажными документами. Одним из первых документов в данном направлении является Декларация принципов и программа действий ООН, в которой были рекомендованы меры, направленные на борьбу с общественно опасными деяниями, как разработать нормы для выявления и расследования, разработать телекоммуникационное оборудование, сетевое программное обеспечение, другие соответствующие продукты и услуги для предупреждения преступлений, облегчения их выявления, расследования и уголовного преследования [4].

Происходящее в мировом сообществе потребовало объединения усилий на международном уровне и разработки методик сбора электронных доказательств. Именно поэтому в рамках международных организаций были приняты законы, регулирующие правила передачи информации о преступлениях в электронном виде. Первый такой документ был принят ООН еще в 1991 году. В нем закреплены методы борьбы с преступлениями в сфере цифровых технологий и компьютеров. Далее Декларация ООН развила Конвенции о преступности в сфере компьютерной информации 2001 г [6].

Организация Объединенных наций работала над вопросом оцифровки правосудия и к 2013 году был достигнут значительный прогресс в этой сфере. Об этом говорится в докладе в г. Вена: наряду с традиционными необходимо внедрять современные методы работы полиции, которые не имеют бумажной формы, а только в электронной форме. При помощи них в ходе судебного разбирательства устанавливаются факты, касающиеся виновности или невиновности лица [5].

Рассмотренный международный опыт свидетельствует о необходимости совершенствования учета и систематизации вещественных доказательств с использованием информационных технологий, авторами предлагается разработать единую автоматизированную систему учета вещественных доказательств и иных изъятых предметов и документов, предусматривающей, в том числе, возможность идентификации изъятого имущества (СУВД ИСОД).

СУВД ИСОД МВД России должна обеспечивать реализацию функций:

- автоматизированный сквозной учет всего изымаемого имущества, включая сданные и найденные предметы и документы;

- учет движения, перемещения упомянутого имущества с момента его изъятия и до окончательного исполнения решения о судьбе объектов учета;

- информационный обмен с внутренними и внешними информационными системами.

СУВД ИСОД МВД России должна включать в себя следующие функциональные подсистемы как ввод-вывод, хранения, моделирования, поддержки принятия решений, защиты информации, администрирования.

Подсистема ввода-вывода предназначена для организации информационного обмена с внешними информационными системами, в том числе создаваемой Минфином России государственной информационной системой учета арестованного, конфискованного и иного изъятого и подлежащего обращению в собственность государства имущества. а также внутренними информационными системами МВД России и сервисами ИСОД МВД России, форматно-логического контроля и преобразования данных с целью решения задач, поставленных перед СУВД ИСОД МВД России.

В подсистему ввода-вывода должны входить следующие модули:

- программные интерфейсы для осуществления форматно-логического контроля в соответствии с заданными правилами;

- набор предустановленных шаблонов документов, соответствующих Правилам оформления графических документов в органах внутренних дел Российской Федерации и Инструкции по делопроизводству в органах внутренних дел Российской Федерации; 
- выполнение структурированных запросов к внешним и внутренним информационным системам, импорт-экспорт структурированных данных в следующих обменных форматах: CSV, XML, JSON, XLS, XLSX, SQL, ODS;

- модуль информационного обмена;

м модуль интеграции.

Модуль информационного обмена предназначен для организации информационного обмена в автоматизированном режиме с формализованными ведомственными, вневедомственными информационными источниками и ресурсами, для которых установлен формализованный порядок такого обмена. Информационный обмен неформализованными ведомственными и вневедомственными источниками и ресурсами должен осуществляться с помощью универсального механизма ручного ввода-вывода данных через пользовательский интерфейс СУВД ИСОД МВД России.

Подсистема хранения должна обеспечивать накопление и хранение массивов данных, эффективную обработку и оперативный доступ к данным СУВД ИСОД МВД России. СУБД предназначена для хранения данных в реляционной форме и решения задач информационно-поискового анализа. В качестве СУБД должна выступать отечественная и/или свободно распространяемая система управления базами данных с открытым исходным кодом.

Объектное хранилище данных должно обеспечивать эффективное хранение сканированных копий документов, мультимедийных файлов, резервных копий и других объектов Объектное хранилище должно обеспечивать надёжное распределённое хранение данных в облачной среде, с возможностью прозрачного масштабирования

по производительности и объёму хранилища. Объектное хранилище данных должно предоставлять возможность загрузки и выгрузки больших объектов по частям. Система управления жизненным циклом документов предназначена для эффективного хранения и коллективного использования текстовых документов, включая аналитические документы, сценарии преобразования данных и схемы документов.
Система управления жизненным циклом документов должна включать в себя распределённую систему управления версиями, которая позволяет эффективно и надёжно хранить несколько версий одного и того же документа, при необходимости, возвращаться к более ранним версиям, определять, кто и когда сделал то или иное изменение. Подсистема защиты информации СУВД ИСОД МВД России должна обеспечивать защиту информации от действующих угроз информационной безопасности в соответствии с Базовой моделью угроз и Базовой моделью нарушителя безопасности информации ИСОД МВД России.

Подсистема администрирования должна обеспечивать возможность многопользовательского режима эксплуатации, настройку, мониторинг, резервное копирование и оперативное восстановление функционирования подсистем СУВД ИСОД МВД России и каналов связи, аудит событий информационной безопасности, ведения списка пользователей и управление правами доступа.

Создание СУВД ИСОД МВД России должно привести к полномасштабному внедрению в повседневную деятельность органов внутренних дел Российской Федерации современных информационных технологий в части централизованного учета вещественных доказательств. Вместе с тем, предполагается получение положительного эффекта по следующим социально-экономическим показателям:

- эффективность выполнения государственных функций за счет сокращения времени и снижения трудоемкости операций по обработке данных, подготовке отчетов и ответов на поступающие запросы;

- снижение трудозатрат на получение, обработку, хранение информации и доведения её до пользователей;

- обеспечение регламентированного доступа к информации сотрудников органов внутренних дел Российской Федерации и необходимого уровня защиты информации.

Реализация СУВД ИСОД МВД России обеспечит системный подход к качественно новому уровню борьбы с преступностью, совершенствованию системы проведения оперативно-разыскных мероприятий, обеспечению сохранности имущества.

\section{ЛИТЕРАТУРА}

1. Постановление Правительства Российской Федерации от 8 мая 2015 г. № 449 г. Москва «06 условиях хранения, учета и передачи вещественных доказательств по уголовным делам»

2. 06 информации, информационных технологиях и о защите информации: Федеральный закон от 27.07.2006 № 149-Ф3 // Собрание Законодательства РФ.— 2006.— № 31.—Ст. 3448; 2016. — № 52.—С. 7491. 
3. Агутин, А.В. Организационно-правовой механизм использования результатов оперативно-розыскной деятельности в отечественном досудебном производстве: монография / А.В. Агутин. - М.: Изд-во Моск. гуманит. ун-та, 2011. — 159 с.

4. Бикмиев, Р.Г. Собирание электронных доказательств в уголовном судопроизводстве / Р.Г. Бикмиев, Р.С. Бурганов. // Информационное право.2015. — № 3.—C. 17-21.

5. Васюков, В.Ф. Теоретические и правовые аспекты расследования преступлений с использованием абонентской информации: монография / В.Ф. Васюков.- Орел: Изд-во «Картуш», 2020.- 339 с.

6. Дубоносов, Е.С. Оперативно-розыскная деятельность: учебник для вузов / Е.С. Дубоносов.— М.: Юрайт, 2013.— 379 с.

7. Краснова Л.Б. Электронные носители информации как вещественные доказательства // Известия тульского государственного университета. Экономические и юридические науки. 2013.— № 4-2.- С. 254-260.

\footnotetext{
๑ Борисов-Потоцкий Андрей Сергеевич ( borisov_pototskiy_@spbu.su ),

Максимов Андрей Сергеевич, Шишичкина Алена Вячеславовна.

Журнал «Современная наука: актуальные проблемы теории и практики»
}
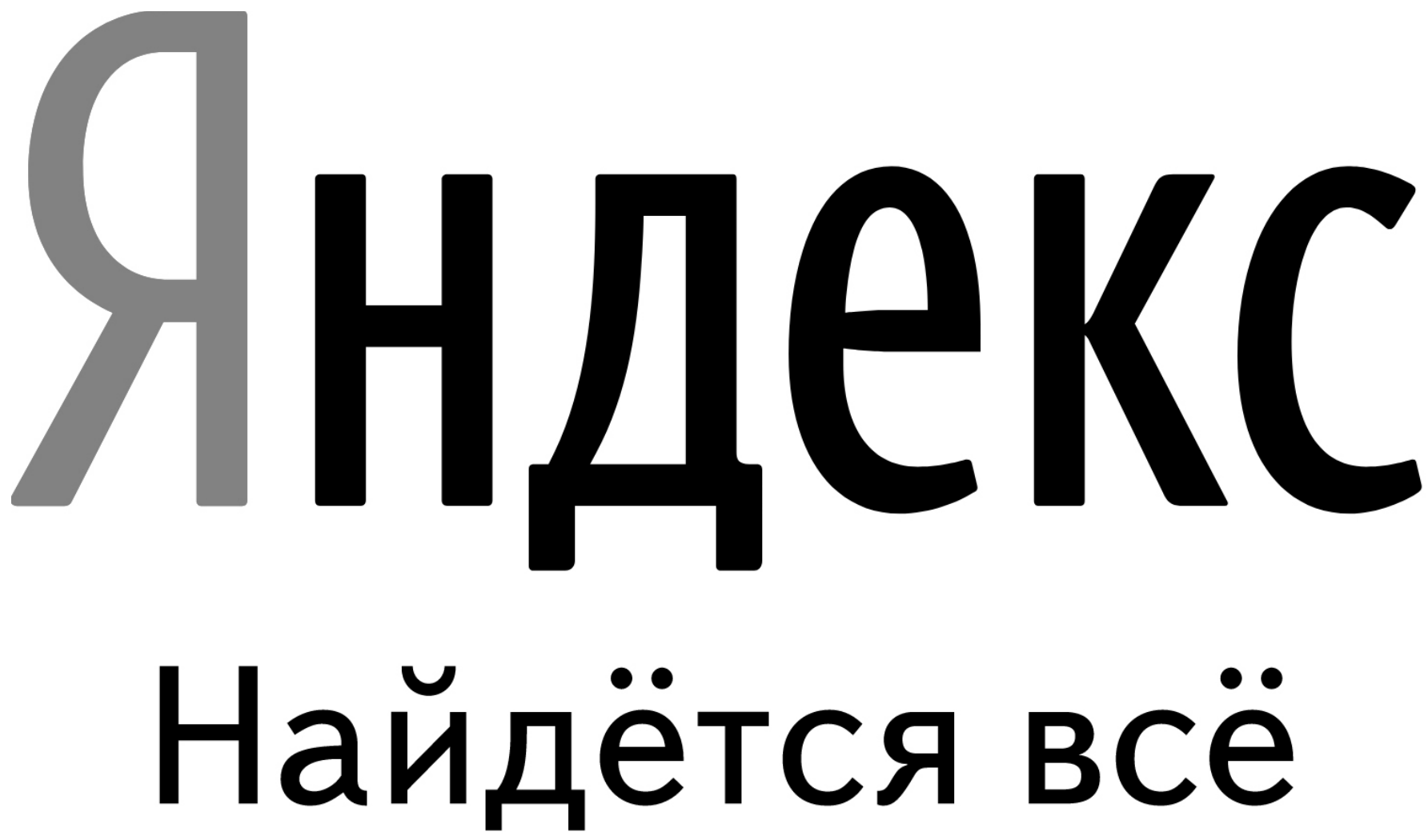